\title{
The storm tracks and the energy cycle of the Southern Hemisphere: sensitivity to sea-ice boundary conditions
}

\author{
C. G. Menéndez ${ }^{1}$, V. Serafini ${ }^{2}$, H. Le Treut ${ }^{2}$ \\ ${ }^{1}$ Centro de Investigaciones del Mar y la Atmósfera/CONICET-UBA, Ciudad Universitaria, Pabellón 2, Piso 2, (1428) Buenos Aires, \\ Argentina \\ ${ }^{2}$ Laboratoire de Météorologie Dynamique/CNRS, Université P. et M. Curie, Tour 15-25, 4 place Jussieu, 75252 Paris Cedex 05, France
}

Received: 18 August 1998 / Revised: 9 June 1999 / Accepted: 30 June 1999

\begin{abstract}
The effect of sea-ice on various aspects of the Southern Hemisphere ( $\mathrm{SH})$ extratropical climate is examined. Two simulations using the LMD GCM are performed: a control run with the observed sea-ice distribution and an anomaly run in which all SH sea-ice is replaced by open ocean. When sea-ice is removed, the mean sea level pressure displays anomalies predominantly negatives near the Antarctic coast. In general, the meridional temperature gradient is reduced over most of the Southern Ocean, the polar jet is weaker and the sea level pressure rises equatorward of the control ice edge. The high frequency filtered standard deviation of both the sea level pressure and the $300-\mathrm{hPa}$ geopotential height decreases over the southern Pacific and southwestern Atlantic oceans, especially to the north of the ice edge (as prescribed in the control). In contrast, over the Indian Ocean the perturbed simulation exhibits less variability equatorward of about $50^{\circ} \mathrm{S}$ and increased variability to the south. The zonal averages of the zonal and eddy potential and kinetic energies were evaluated. The effect of removing sea-ice is to diminish the available potential energy of the mean zonal flow, the available potential energy of the perturbations, the kinetic energy of the growing disturbances and the kinetic energy of the mean zonal flow over most of the Southern Ocean. The zonally averaged intensity of the subpolar trough and the rate of the baroclinic energy conversions are also weaker.
\end{abstract}

Key words. Air-sea interactions - Meteorology and atmospheric dynamics (climatology; ocean-atmosphere interactions)
Correspondence to: C. G. Menéndez

E-mail: menendez@atl.fcen.uba.ar

\section{Introduction}

There has been a statistically significant increase in temperature since the mid-1940s in some regions of the Antarctic periphery (Harangozo et al., 1994; Turner et al., 1997). The reason for this observed warming is not fully understood at present, but it may be related to changes in the sea-ice extent and in the regional atmospheric circulation. A comprehensive understanding of the interaction between the sea-ice and the atmospheric circulation is therefore necessary. Current climate models diverge in their estimation of the climate change scenarios at the high latitudes of the Southern Hemisphere (e.g. Carril et al., 1997). This may be in part due to the complexity of sea-ice physics and dynamics that is parameterized in a different manner in each model. It seems likely that many physical processes occurring in those regions are not efficiently represented in the coupled models.

In order to understand the model sensitivity and to assess the possible impact of a climatic change it is useful to study how the melting of sea-ice, and the corresponding warming of the surface temperature, may affect the extratropical circulation of the Southern Hemisphere (hereafter SH). These circulation changes are related to basic characteristics such as the atmospheric energy cycle and the storm tracks. We try to estimate the role of sea-ice on the $\mathrm{SH}$ atmospheric circulation, as a limited approach for understanding and simulating high-latitude climate change. In particular, although the interaction between sea-ice characteristics and the cyclonic activity is rather complex, the aspect we wish to address is the importance of changes in the sea-ice cover for the climatological high-frequency behaviour in the southern extratropics.

Most of the Antarctic sea-ice melts in summer and forms again in winter, covering up to $18 \times 10^{6} \mathrm{~km}^{2}$. Compared with the Arctic, the percentage of open water is greater and the ice thickness is smaller. Other sea-ice 
morphology differences between the SH and the Northern Hemisphere are related to the latitude domain and the location relative to the continents. The presence of sea-ice first affects the vertical transfer of energy between the atmosphere and the surface. Turbulent heat fluxes are substantially reduced over sea-ice. Surface roughness values in the standard parameterizations are larger over sea-ice than over the ocean affecting the surface exchange of momentum. In addition, the high reflectivity of sea-ice reduces the absorption of solar radiation by the surface.

However the Antarctic sea-ice and the neighbouring ocean is also a region of high cyclone frequency and cyclogenesis at the synoptic and mesoscale (Bromwich, 1991; Carleton, 1992). Thus, one might expect a relationship between surface conditions and cyclone behaviour. This connection between sea-ice extent, cyclonic activity and features of the circulation is not completely clarified. Carleton (1989) and Streten and Pike (1980), for example, found little observational evidence to support this relationship. However, insufficient or poor data in southern high latitudes affect the observational studies. Simmonds and Wu (1993) (hereafter SW93) discuss the ambiguous nature of the presently published studies concerning the response of the atmosphere to sea-ice perturbations. Ambiguity can arise from the, usually, short periods of data being used, the particular epoch being considered and the highly variable character of the synoptic circulation in the southern extratropics. In a recent observational analysis, Godfred-Spenning and Simmonds (1996) have found that a sea-ice-cyclone link is not apparent over the entire sea-ice zone on a seasonal time scale, supporting the conclusion of Carleton (1989) and Streten and Pike (1980).

Sensitivity studies using general circulation models (GCMs) therefore constitute an important approach to understand the climate of these high-latitude regions. Previous numerical studies have analyzed the atmospheric response to reductions in the Antarctic sea-ice extent or concentration (Simmonds, 1981; Mitchell and Hills, 1986; Simmonds and Dix, 1986; Mitchell and Senior, 1989; Simmonds and Budd, 1991; SW93). In most cases, these GCM experiments (winter simulations) only report some evidence that the sea-ice forces the atmospheric circulation in the circumpolar trough region. A local decrease in surface pressure was generally found, especially in the region from which sea-ice was removed. SW93 have studied the sensitivity of cyclone behaviour to prescribed changes in winter Antarctic sea-ice concentration. They show an increase in the number of cyclones near the Antarctic coast (particularly over most of the Weddell and Ross seas) and a decrease in the cyclone frequency to the north, in response to the reduction of sea-ice concentration. However the intensity of these extratropical cyclones becomes weaker. SW93 suggest that the climatological decrease in pressure results essentially from an increase in cyclone numbers near the coast as opposed to a deepening of existing cyclones. Recently, Menéndez et al. (1999) (hereafter MSLT99) performed a sensitivity experiment in which all southern sea-ice was removed with a relatively high-resolution atmospheric global model in order to study the effect of sea-ice on the poleward transport of heat and momentum by eddies and the mean eddy statistics. MSLT99 found that the removal of ice in the Southern Ocean affects the baroclinic structure of the atmosphere. In general, the meridional wind variance, the poleward transient temperature flux and the eddy flux convergence of westerly momentum were weaker over the Southern Ocean when sea-ice was removed. Le Treut and Kalnay (1990) also suggest that the simulated cyclone life cycle and the cyclone tracks may, in part, be dependent on the prescriptions of the boundary conditions (sea-surface temperature and sea-ice extent), especially in the high southern latitudes.

In this study two simulations of an atmospheric climate model are compared: a control run with the observed sea-ice distribution and an anomaly run in which all SH sea-ice was replaced by open ocean. Section 2 presents the model, the experiment design and a brief evaluation of the basic climatology. Section 3 examines the effect of sea-ice on various aspects of the southern extratropical climate. The impact on some basic characteristics is described, together with the circumpolar trough and its semi-annual oscillation, the high frequency variability and the storm tracks, and the energy cycle. A general discussion is given in sect. 4 .

\section{Model description, experiment design and model evaluation}

\subsection{The model}

The model being used is the general circulation model of the Laboratoire de Météorologie Dynamique du CNRS (LMD GCM). This model is formulated in finite differences, in its dynamical part, and contains comprehensive physics. Sadourny and Laval (1984) first described the original version of the model. The present version, called Cycle 5, contains a number of new features. The cloud scheme is a prognostic scheme based on a budget equation for cloud water ( $\mathrm{Li}$ and Le Treut, 1992). Convection is parameterized by a combination of a Kuo (1965) scheme and a moist adiabatic adjustment. The radiation scheme is the same as used operationally at ECMWF, with a representation of the transfer of solar radiation following the scheme of Fouquart and Bonnel (1980). The infrared radiation is parameterized following Morcrette (1990). Some refinement of the surface parametrization and a description of the main climatology of the model are available in Harzallah and Sadourny (1995). Note however that our simulations are different from those of Harzallah and Sadourny (1995) because they include a different sea surface temperature (SST) climatology. An open seawater fraction in all polar sea-ice is considered in the model. Sea-ice is allowed to cover a fraction of the grid only, but the computation of all fluxes is carried out using mixed coefficients, which correspond to an average over the 
whole grid area. The surface albedo (in particular the sea-ice albedo) parametrization is described in Chalita and Le Treut (1994). The model resolution corresponds to a grid of 64 points in longitude, 50 points in latitude and 11 vertical layers. Note that the version of the LMD GCM used in this work is similar to the model used in MSLT99, but with lower resolution $(96 \times 72 \times 19$ in MSLT99).

\subsection{General design of the experiment}

In the present work we consider as control simulation a standard simulation using the Cycle 5 LMD GCM and climatological sea surface temperatures (SST) for the period 1970-1988, with no interannual fluctuations. A second simulation (hereafter referred as "NOICE") was made, in which all Antarctic sea-ice was removed. By removal we mean setting again the albedo and surface drag to the values of seawater, and imposing a prescribed SST of $-2{ }^{\circ} \mathrm{C}$ (freezing point of seawater), as it has been used in previous ice-free experiments (e.g. MSLT99). This type of imposed surface forcing signifies that we assume that the ocean has enough heat storage to be able to provide the upward heat flux needed to prevent the sea-ice from reappearing. Certainly, this is not a very realistic supposition since it implies infinite oceanic heat capacity. However, the present experiment is only a preliminary sensitivity experiment with rather unreal surface forcing.

The climates of the control and anomaly runs were estimated from the analysis of two 5-y simulations with full seasonal cycle. The duration of our experiment, as many previous, similar sensitivity experiments for the removal of Antarctic and Arctic sea-ice found in the literature (e.g. Mitchell and Senior, 1989 averaged their results over nine months, Royer et al., 1990, analyzed the second winter after an annual cycle model integration) is relatively short, even if we take into account the absence of interannual variability of the SST. As the dynamical fields in the southern extratropics are highly variable on an interannual time scale, a longer than $5 \mathrm{y}$ simulation would be desirable to describe fully the variability of the circulation. This is why, in this exploratory work which is also using a low resolution of the model, we restrict the analysis to basic elements of the SH climate, and to the mean zonal energetics of the atmosphere.

A large amount of forcing (with no interannual variations) was chosen for the sake of enhancing the signal-to-noise ratio and reducing the need to test the statistical significance of the results. From the physical consistency of the results, we will be able to infer that the sea-ice-atmosphere associations are genuine and did not merely arise through a coincidence of anomalies in the analyzed simulations. In this sense, the extreme surface anomaly in NOICE should help to make a clearer representation of the interactions between the different physical and dynamic processes. However, this large change in sea-ice concentration (from observed to $0 \%$ ice coverage and without interannual variations) is not realistic, so caution must be exercized before generalizing our results to the more moderate and highly variable perturbations in ice condition that are actually observed.

\subsection{Simulated SH climate}

The control climate of this version of the LMD GCM is similar to those reported for the Atmospheric Model Intercomparison Project (AMIP) (e.g. Le Treut et al., 1995). The tropospheric circulation in the SH presents some remarkable characteristics such as a deep circumpolar trough all the year round, a double westerly jet in winter and a semiannual oscillation of sea level pressure and other quantities. The ability of the model to reproduce these features represents a good test of the model's fidelity. The observational-based climatology is estimated using the ECMWF operational analyses. The observed mean sea level pressure for summer (Fig. 1a) presents a circumpolar trough near $65^{\circ} \mathrm{S}$, a steep midlatitude meridional gradient and a subtropical ridge with centres in the eastern part of the oceans. In winter (Fig. 1b) the observed subAntarctic trough is somewhat deeper than in summer and the subtropical ridge intensifies and shifts northward. In the simulation (lower panels), in common with other low resolution GCMs (Xu et al., 1990), the subpolar trough is too weak and lies too far north throughout the year, although it tends to be better simulated during winter. The subtropical highs are too zonal and somewhat underestimated, but the equatorward shift of the ridge from summer to winter is captured by the model. The meridional pressure gradient is too weak especially in summer.

The tropospheric circulation over the Southern Ocean displays a marked half-yearly cycle. This semiannual oscillation (SAO) produces a twice-yearly poleward migration and intensification of the circumpolar trough with equinoctial maxima in baroclinity and in the strength of westerly winds in the troposphere south of about $50^{\circ} \mathrm{S}$. Several authors (e.g. Schwerdtfeger and Prohaska, 1956; Schwerdtfeger, 1960; van Loon and Rogers, 1984; Meehl, 1991; Simmonds and Jones, 1998) have documented this phenomenon and its variability. To evaluate the simulation of this half-yearly wave, Fig. 2 shows the mean annual cycle of the second harmonic of the zonally averaged intensity of the circumpolar trough determined through Fourier analysis. $\mathrm{Xu}$ et al. (1990) emphasize that most of the low-resolution GCMs fail to simulate this large-scale characteristic of the annual cycle in the southern midand high latitudes. Other studies (e.g. Tzeng et al., 1993) manifest improvements in simulating some features of the SAO. The amplitude of the second harmonic simulated by this version of the LMD GCM agrees well with the oscillation derived from the analyses. However, the phase is shifted by about one month.

The observed and simulated mean zonal wind at $500 \mathrm{hPa}$ for summer and winter is shown in Fig. 3. In winter (Fig. 3b) the subtropical jet reaches its maximum intensity to the east of Australia. Near South America, 
(a)

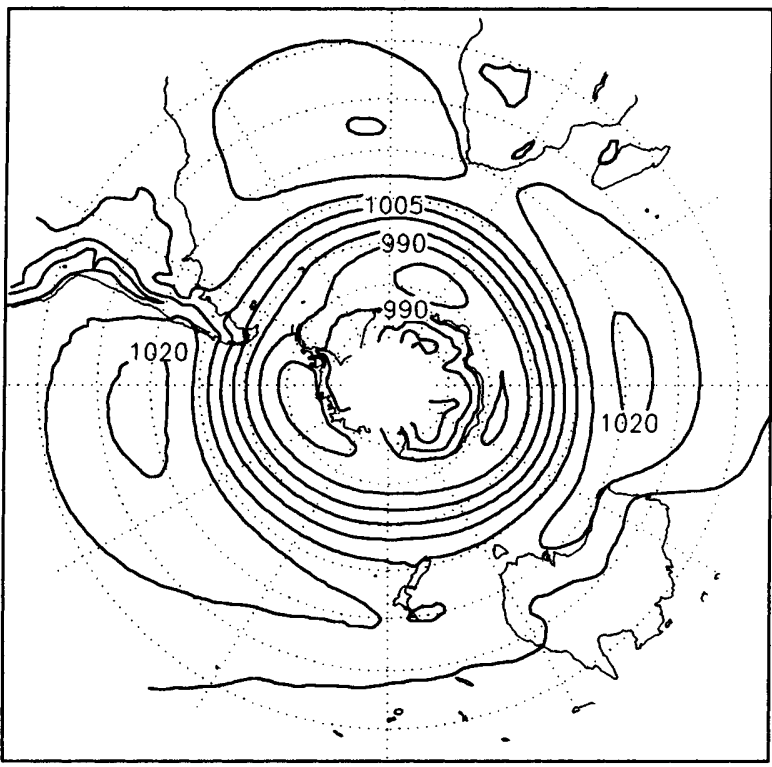

(c)

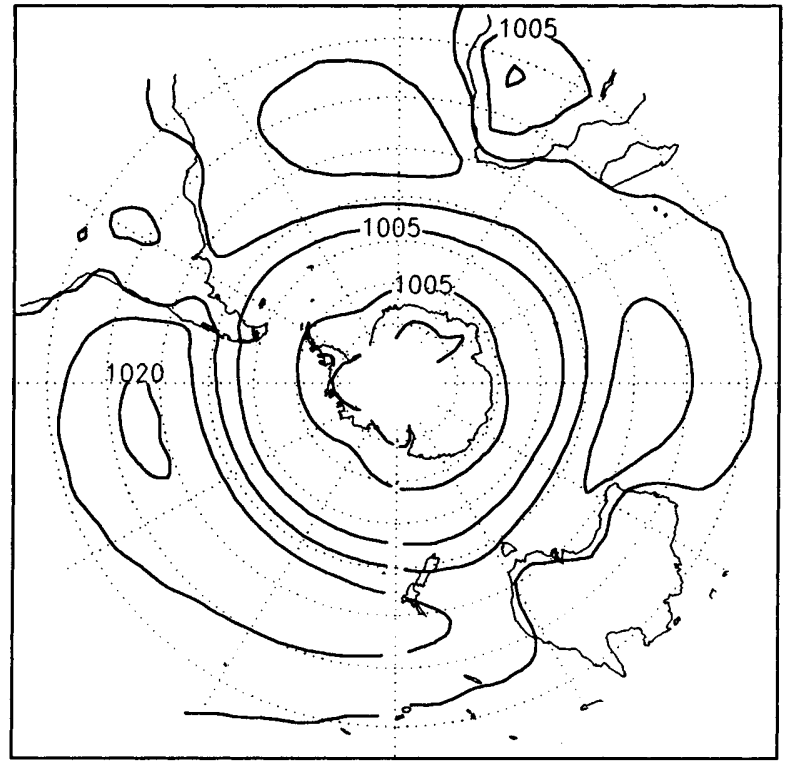

(b)

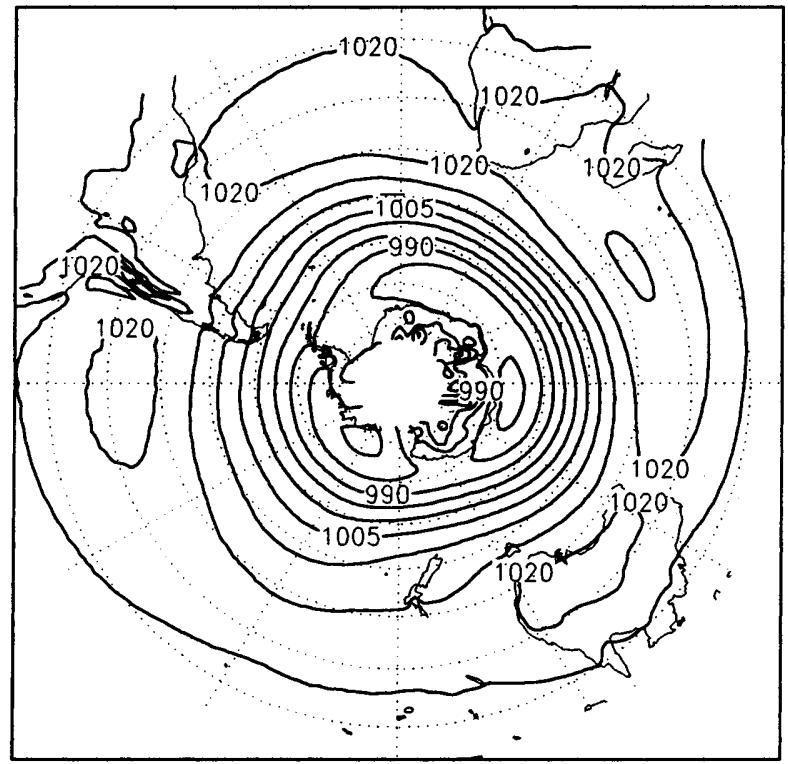

(d)

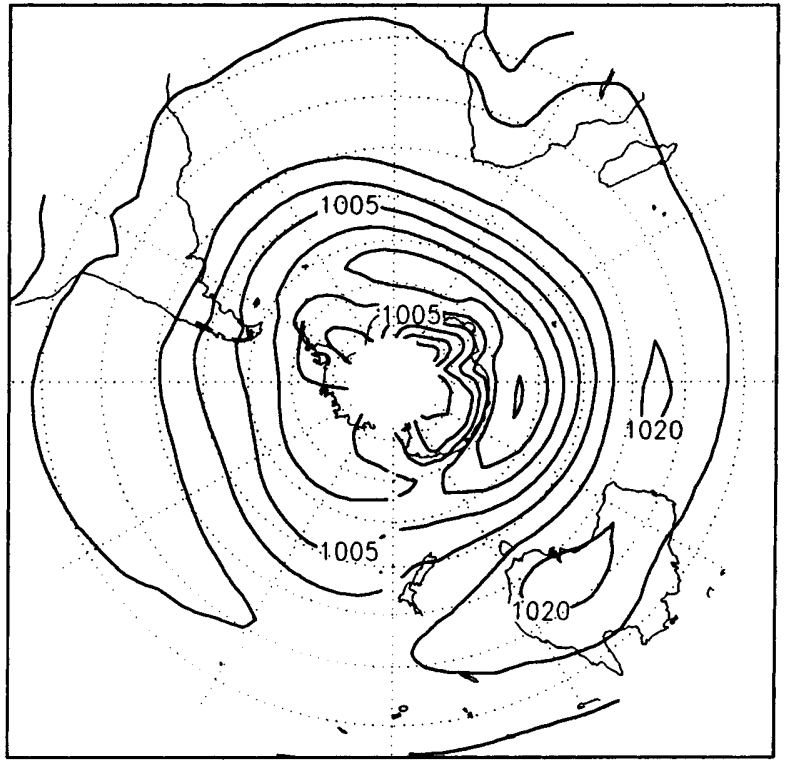

Fig. 1a-d. Mean sea level pressure from observations (upper panels) and the model (lower panels), for summer (a, c) and winter (b, d). Contour interval is $5 \mathrm{hPa}$

the axis of the jet begins to spiral in toward the pole, producing a double jet over part of the hemisphere. The main features of the simulated fields (lower panels) are similar to the observational climatology but the model tends to produce a jet that is too zonal, especially in summer. The polar branch of the westerlies and the zonal wind minimum over the southern Pacific are poorly captured by many GCMs (e.g. Boville, 1991; Tzeng et al., 1993; Katzfey and McInnes, 1996). However, the wintertime split jet structure is apparent in the LMD GCM control simulation. The zonal wind minimum is quite well captured near New Zealand. In general, the subtropical jet tends to be stronger and the polar jet weaker than in the analysis.

\section{Results}

\subsection{General features}

As mentioned the most immediate effect of removing sea-ice is to raise the surface temperature. In our experiments this effect is prescribed. Warming of the overlying atmosphere is mainly confined near the surface. The atmospheric disturbances distribute this warming over a range of latitudes. Figure 4 shows the annual cycle of temperature averaged between $55^{\circ} \mathrm{S}$ and $70^{\circ} \mathrm{S}$ in the model's lowest sigma level $(\sigma=0.991)$. The near-surface temperature augmentation is important in winter, but is negligible between November and April. 


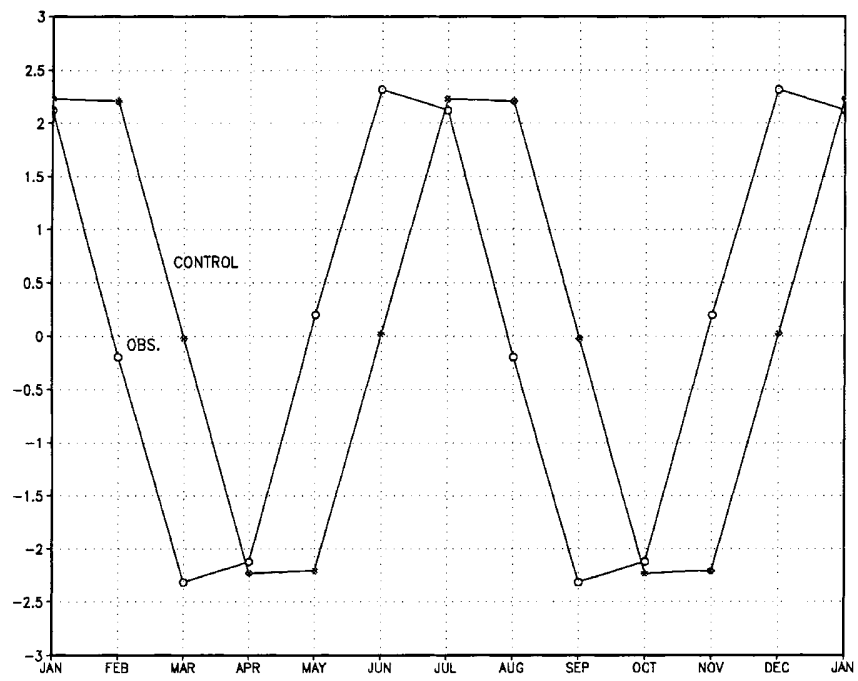

Fig. 2. Mean annual cycle of the second harmonic of the zonally averaged intensity of the subpolar trough from observations and the model (in $\mathrm{hPa}$ )

The largest temperature increase in winter is located over the Weddell Sea at about $20^{\circ} \mathrm{W}$ and between $160^{\circ} \mathrm{E}$ and $120^{\circ} \mathrm{W}$ in the Pacific sector (Fig. 5a). Noted that we computed our diagnostics over a three-month period (austral winter - June, July, August - or summer December, January, February) instead of a one-month period (as in most previous similar sensitivity studies). The use of a longer period has the advantage of reducing the noise level of the results and consequently increases their significance and reliability. In winter large surface heat fluxes into the atmosphere occur to the north of the ice edge. The higher fluxes are produced by the outbreaks of cold dry air from the Antarctic continent. The location of the maximum for the sensible heat flux into the atmosphere shifts poleward in the NOICE simulation. There is a decrease in the flux near the location of the ice edge, as prescribed in the control experiment, and a large increase in the regions corresponding to the largest temperature increase (Fig. 5b). Surface heating intensifies the mean upward motion over the sea-ice (not shown). This dynamical response is compensated by relative descent northward of the ice edge and over Antarctica. Figure 2c shows the changes in mean sea level pressure. It displays both negative and positive anomalies near the Antarctic coast. The largest pressure decrease near Antarctica is found at the regions of largest increase in surface temperature (i.e. over the Weddell and Ross seas). Equatorward of the control ice edge there are pressure rises over the southern oceans.

\subsection{Zonal wind}

Sea surface temperatures and temperature gradients in the lower troposphere are strongly correlated in the $\mathrm{SH}$ (van Loon, 1972). The meridional temperature gradient is closely linked to the zonal winds through the thermal wind relationship. The presence of the Antarctic continent and its associated pack ice provides a heat sink throughout the year, affecting the meridional temperature gradients. The polar jet is influenced by the strong temperature gradient that appears in the lower troposphere adjacent to Antarctica. Removing sea-ice may affect the meridional temperature gradient and thus the $\mathrm{SH}$ jet structure. Figure 6 displays the changes in the mean zonal wind at $500 \mathrm{hPa}$. The meridional temperature gradient (not shown) is reduced over most of the southern Atlantic and Indian oceans, probably as a consequence of the changes in the distribution of the surface heat fluxes. Consequently the polar jet is weaker in NOICE and the double jet structure is less evident. In contrast, the subtropical jet is more zonally elongated in NOICE. The zonally averaged mean zonal winds (not shown) are decreased throughout the troposphere southward of $30^{\circ} \mathrm{S}$, except in a shallow boundary layer over the sea-ice anomaly. Northward of this, there is a latitude band between about $10^{\circ} \mathrm{S}$ and $30^{\circ} \mathrm{S}$ where winds are increased in the NOICE case.

\subsection{SAO of the subpolar trough}

As noted previously, an important feature of the $\mathrm{SH}$ climatology is the SAO of the circumpolar trough. The trough is more intense and is located farthest south in March-April and September-October in the observational climatology (see Fig. 2). The circumpolar trough is influenced by the collective tracks of individual baroclinic disturbances: depressions that develop within the circumpolar trough and move eastwards or those that move into the Antarctic coastal area from the north or northwest (Jones and Simmonds, 1993). As the annual cycle of this transient eddy activity is also modulated by the SAO (Meehl, 1991), it is interesting to examine the model sensitivity from this point of view. Its major cause is the difference in the seasonal heating and cooling between middle and high latitudes. An intensification of the temperature gradient between the oceanic latitudes and the Antarctic latitudes is produced twice a year in the midtroposphere. This behaviour is dependent on the heat budget of the oceanic upper layers, which is affected by the annual cycle of sea-ice. To illustrate the effect of sea-ice on the SAO, the mean annual cycle of the second harmonic of the zonally averaged intensity of the circumpolar trough for the control and NOICE simulations are compared in Fig. 7. The phase is maintained in the anomaly run. But the amplitude is substantially reduced in NOICE. Besides the effect on the semi annual component, the trough tends to be weaker between May and July when sea-ice is removed (not shown here).

\subsection{Filtered standard deviation of the sea level pressure}

We study here the impact of the sea-ice on the simulated high frequency transient features of the circulation. The 
(a)

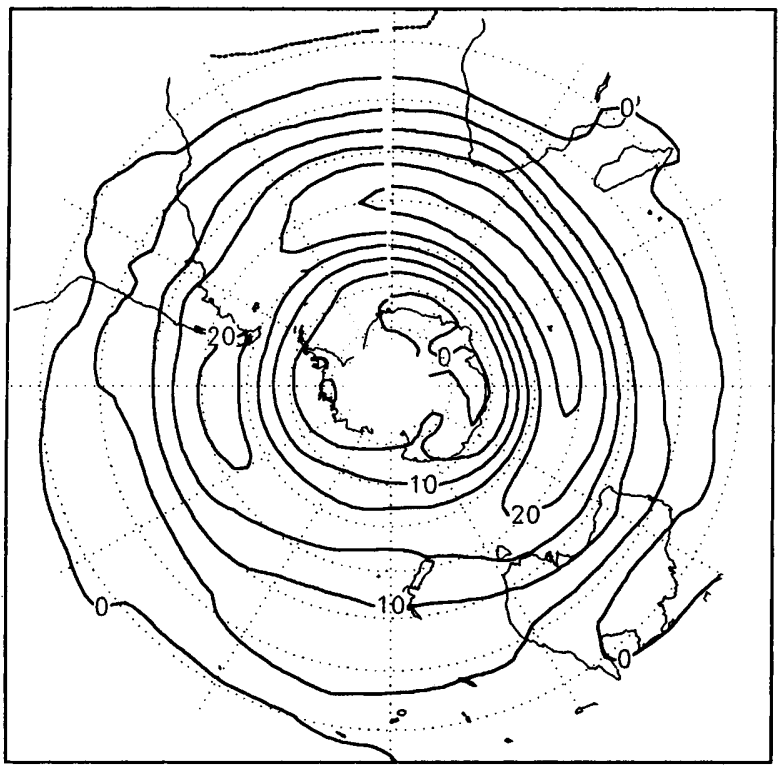

(c)

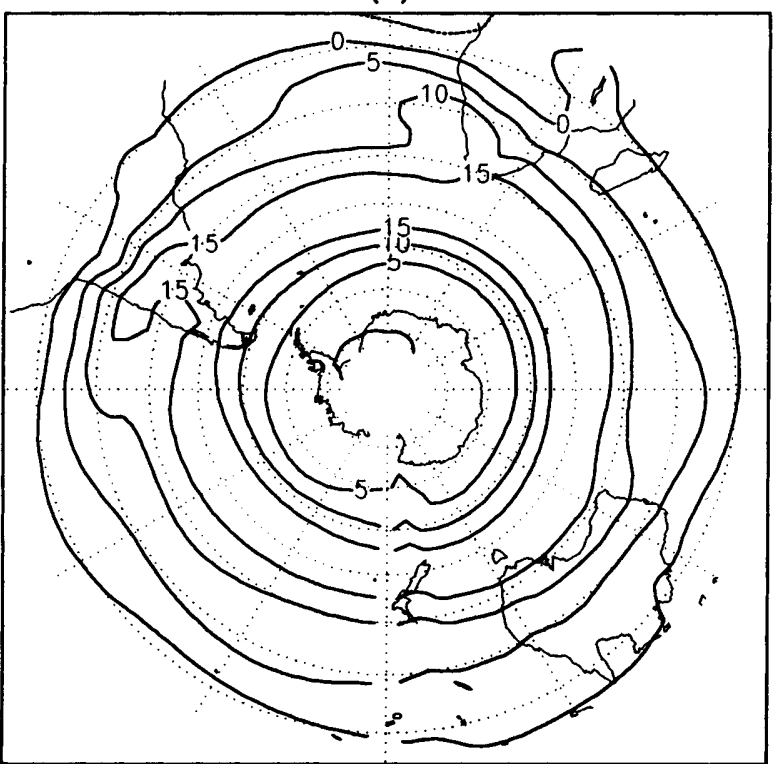

(b)

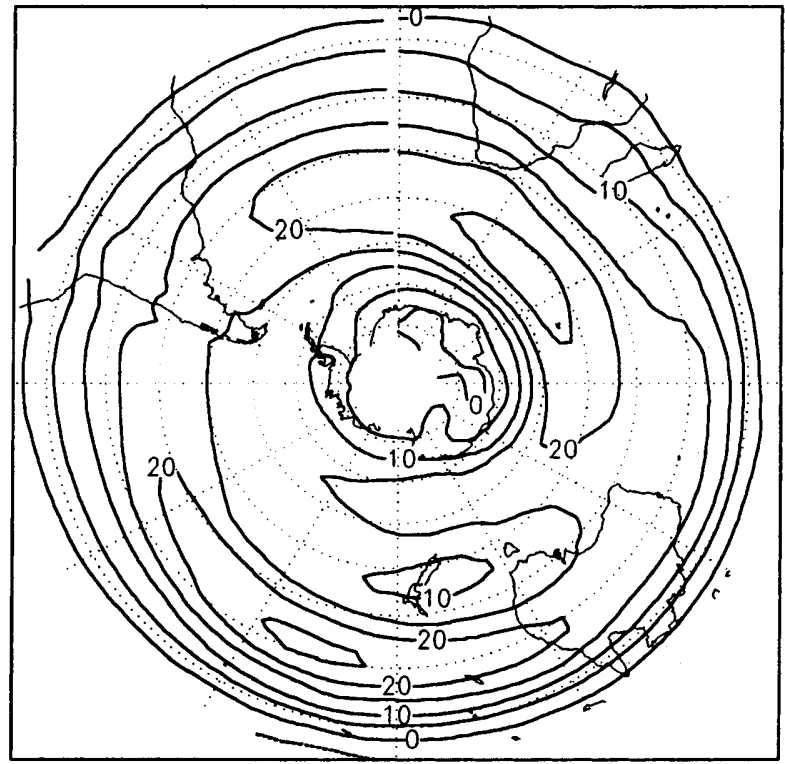

(d)

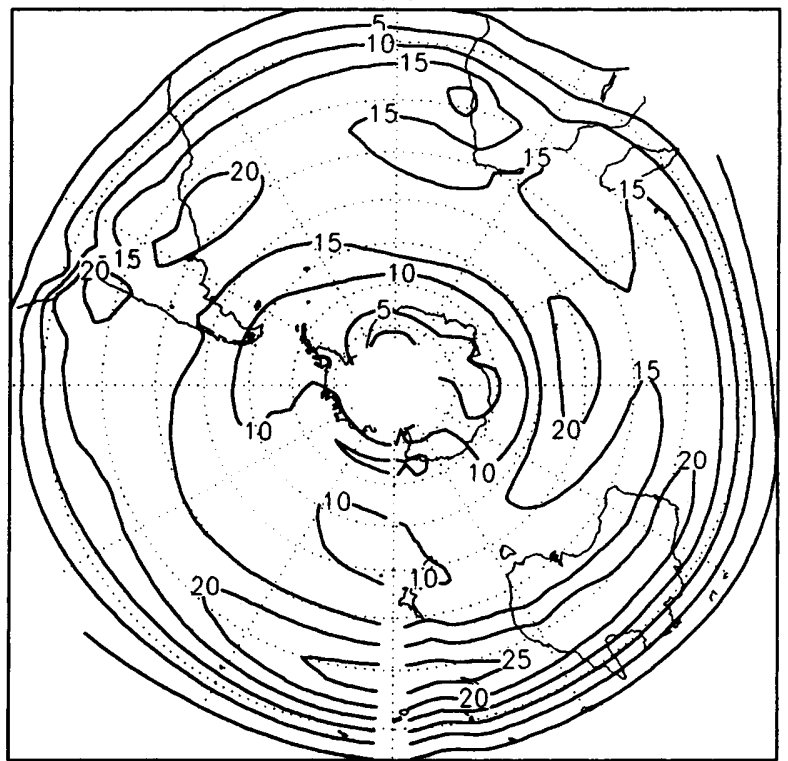

Fig. 3a-d. Mean zonal wind at $500 \mathrm{hPa}$ from observations (upper panels) and the model (lower panels), for summer (a, c) and winter (b, d). Contour interval is $5 \mathrm{~ms}^{-1}$

variability in the synoptic time scale was investigated utilizing a filter based on the procedure formulated by Murakami (1979). This technique has the advantage that we can specify at our convenience the maximum in the response curve, and its bandwidth (as shown in Murakami, 1979). In this sensitivity experiment, the largest effect can be expected where sea-ice extent is the largest (i.e. in western Antarctica). Synoptic systems in this region tend to displace and develop more slowly than elsewhere in the Southern Ocean (Berbery and Vera, 1996). The phase speeds of the synoptic waves are smaller in the South Pacific Ocean than in the main storm track region (i.e. the South Indian Ocean).
According to Berbery and Vera (1996), their dominant period in the South Pacific sector is about 8 days (in comparison with a period of about 4 days in the Indian Ocean). For this reason, the bandpass filter applied here covers a period range from about 3-9 days with the centre at day 6 . The distribution of the filtered standard deviation of the sea level pressure for both simulations is represented in Fig. 8. As shown by Simmons and Hoskins (1978) waves with periods up to 10 days have a variance related to baroclinic instability.

In winter, the control experiment shows a high level of synoptic scale variability over the high-latitude oceans, particularly over the Atlantic Ocean between 


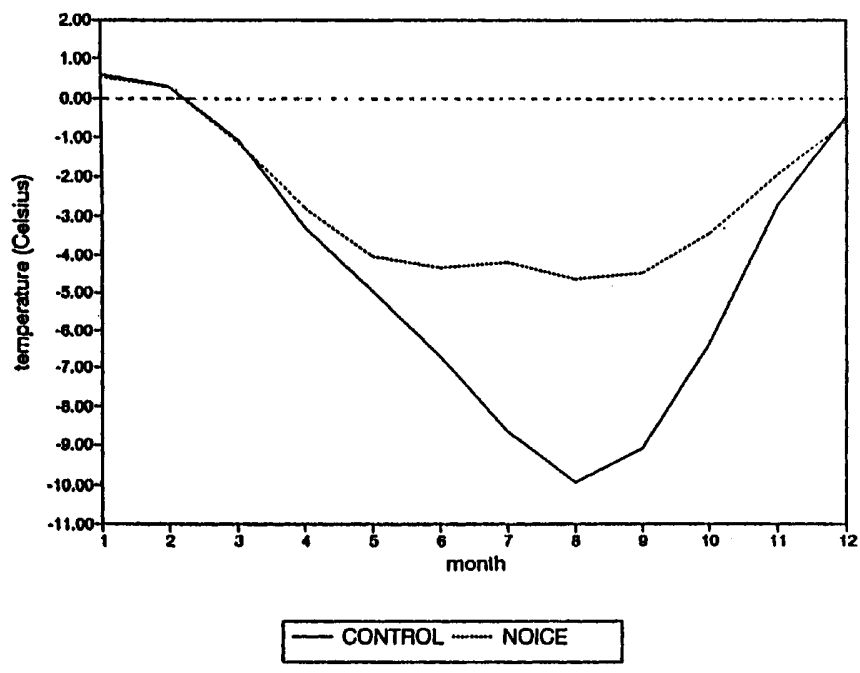

Fig. 4. Mean seasonal variation of the temperature in the model's lowest sigma level, averaged between $55^{\circ} \mathrm{S}$ and $70^{\circ} \mathrm{S}$, in ${ }^{\circ} \mathrm{C}$

$40^{\circ} \mathrm{S}$ and $60^{\circ} \mathrm{S}$ and over the Pacific Ocean in the Bellingshausen/Amundsen Sea. It can be seen that the area of the Bellingshausen/Amundsen Sea has a larger standard deviation than any other area of the circumpolar trough. When comparable fields are produced using UK Meteorological Office, US NCEP and the Australian Bureau of Meteorology analyses, the largest standard deviation is also present over this area (Turner et al., 1997). This region is characterized by a large standard deviation in the number of individual cyclones and also in the cyclone density, which takes account of the number and speed of the individual lows. Turner et al. (1997) reported that an atmosphere-only version of the Hadley Centre climate model also succeed in reproducing this pattern. According to these authors the fact that the circulation variations in this region are well reproduced by atmosphere-only GCMs with prescribed surface conditions indicates that is not associated with inter-annual variability in the ocean condition. In summer, there is a belt of high variability around the hemisphere at about $40^{\circ} \mathrm{S}-60^{\circ} \mathrm{S}$ with maxima over the three oceans. Compared to winter, the simulated summer synoptic variability is weaker and with more zonal symmetry.

Not surprisingly, in the NOICE simulation the major anomalies are observed in winter. The wintertime sea level pressure variability over the southern South Pacific, particularly over the Bellingshausen/Amundsen sector, is decreased and the maximum over the Atlantic is more elongated eastward. These differences can be better observed in Fig. 9 which shows the anomalous (i.e. change from the control) geographical distribution of the filtered standard deviation of sea level pressure for winter. The general tendency apparent in this figure is a decrease of the short-term variability in the neighbourhood of Antarctica as the sea-ice is eliminated, mainly in the Pacific sector and over the Weddell Sea. The decrease is especially evident over and northward of the ice edge (as prescribed in the control). That is, in the NOICE case the amplitude or the density (a)

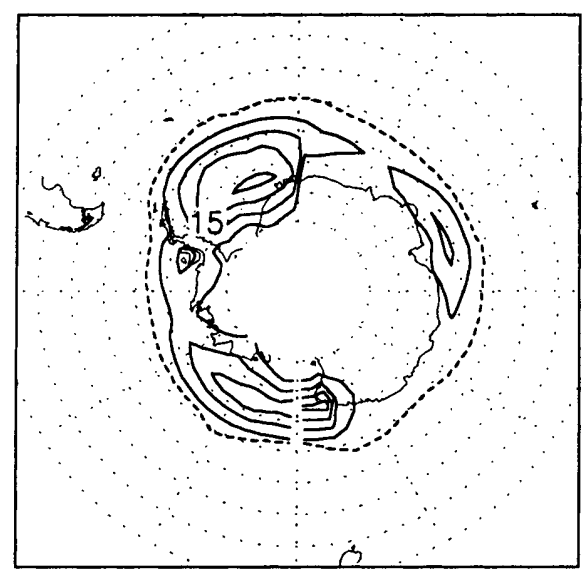

(b)

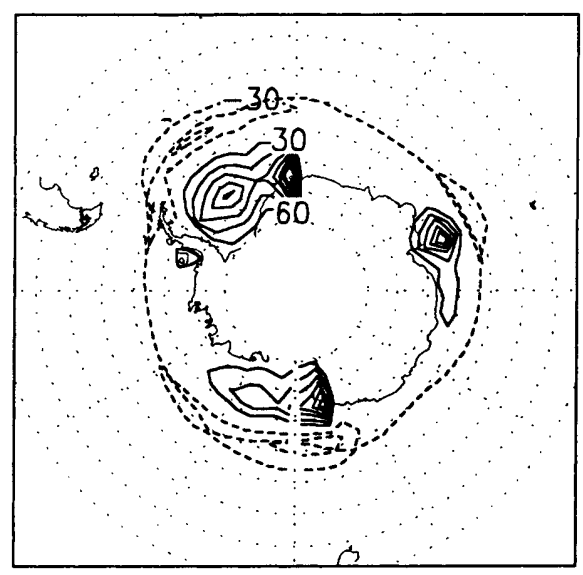

(c)

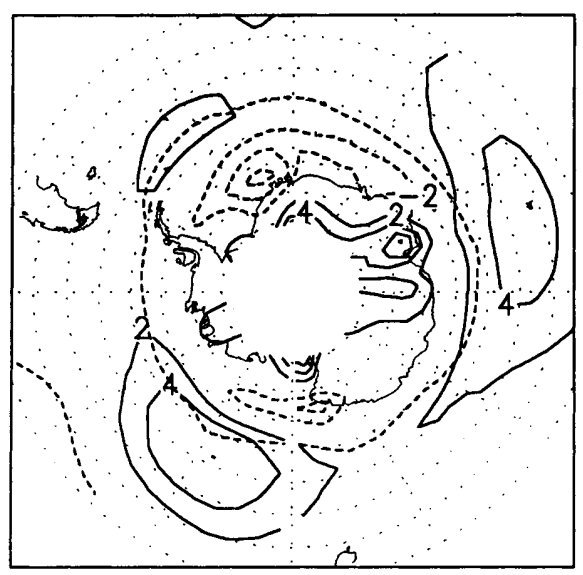

Fig. 5a-c. Mean winter anomalies (NOICE minus control): a changes in temperature at the model's lowest sigma level, every $5{ }^{\circ} \mathrm{C}$. b Changes in sensible heat flux, every $30 \mathrm{Wm}^{-2}$. c Changes in mean sea level pressure, every $2 \mathrm{hPa}$. The zero contours are not shown. The dashed line around Antarctica indicates the mean sea-ice extent for winter in the control simulation. The northern latitude is $40^{\circ} \mathrm{S}$

of the high frequency perturbations over this region of the sub-Antarctic trough is diminished. Another region of decreased variability is observed over the South 
(a)

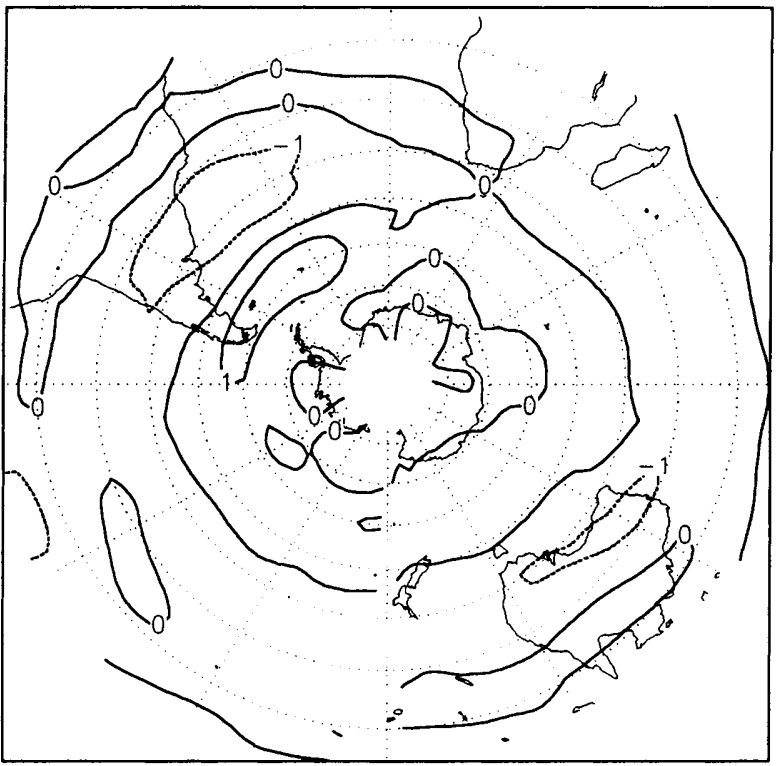

(b)

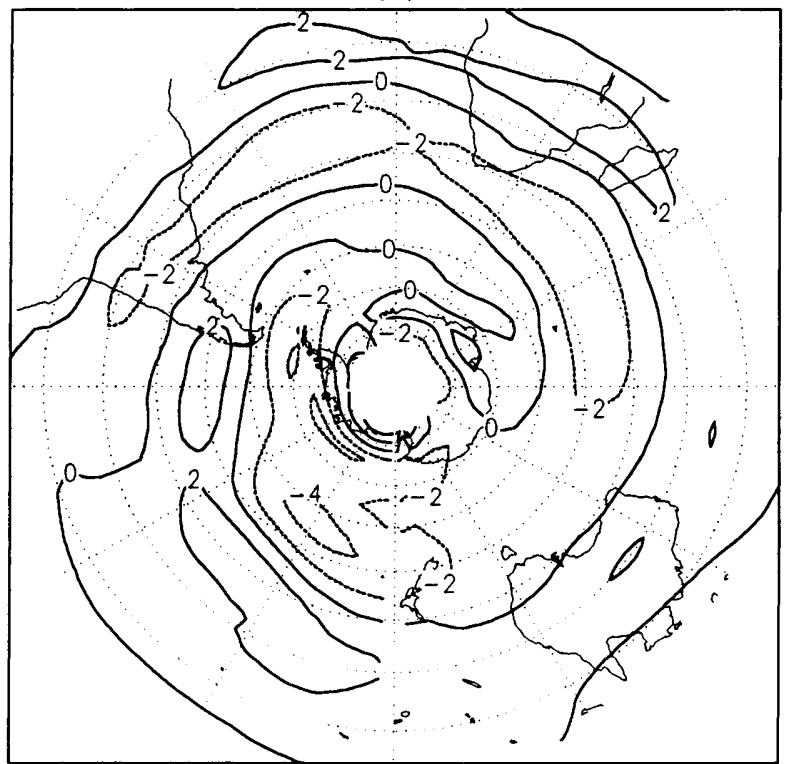

Fig. 6a, b. Changes (NOICE minus control) in mean zonal wind at $500 \mathrm{hPa}$ for a summer and b winter. Contours every $1 \mathrm{~ms}^{-1}$ (a) and $2 \mathrm{~ms}^{-1}$ (b)

Atlantic at about $45^{\circ} \mathrm{S}$. Nevertheless, there are some sectors which show up as regions of increased synoptic variability when sea-ice is removed. This is the case over the Antarctic coasts, especially over the eastern continental sector. Another region with increased high frequency variability is found over South America near $40^{\circ} \mathrm{S}$. The longitudinal differences in the anomaly may be related to the sea-ice distribution in the control run: it has removed more ice in the western than in the eastern sector. Nevertheless, these longitudinal differences may also suggest that perturbations are influenced by other factors besides the sea-ice (e.g. baroclinic and barotropic processes, the interaction of the high topography of Antarctica with the large-scale flow, etc.).

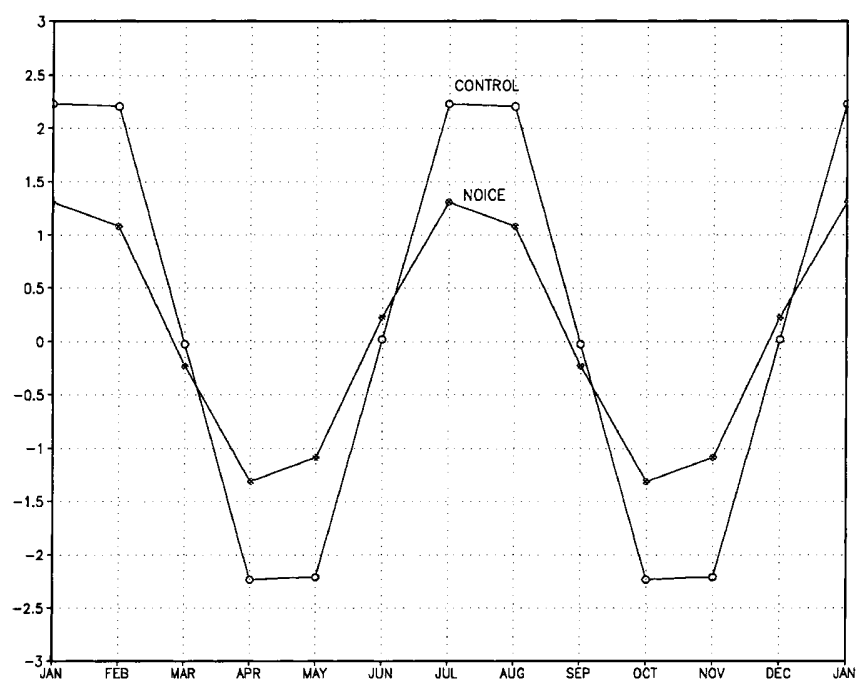

Fig. 7. Mean annual cycle of the second harmonic of the zonally averaged intensity of the subpolar trough for the control and the NOICE simulations (in $\mathrm{hPa}$ )

\subsection{The storm track}

The eddy activity associated with the SH storm tracks is mostly related to baroclinic systems (Trenberth, 1991). In the $\mathrm{SH}$ winter large weather systems propagate into the upper level subtropical jet while at low levels baroclinic waves are maintained in the subpolar jet (Hoskins et al., 1983). The SH storm tracks are also influenced by a strong barotropic (height independent) component in the mean westerlies (James and Gray, 1986). This barotropic component (not analyzed here) is quite well captured by the model. However, the eddy energy generation is mainly due to baroclinic processes while barotropic processes are weaker. Largest values of baroclinicity occur along the regions of maximum winds (as shown in Berbery and Vera, 1996 their Fig.1, the geographical distribution of the jet streams is similar to the Eady growth rate).

We describe here the impact of sea-ice on the filtered variance of geopotential height in the upper troposphere $(300 \mathrm{hPa})$. We use the same filter as described previously. This variance arises from the higher frequency transient activity (i.e. disturbances with periods less than about 10 days). The major axis of the storm tracks approximately corresponds to the paths commonly followed by active depression centres. As we have shown before, the sea-ice removal affects the surface heat flux distribution, the temperature gradient and thus the baroclinicity and the polar jet. Furthermore, the weakness of the polar jet in the NOICE case is important because any perturbation is transported more slowly, thereby limiting the local standard deviation of geopotential height. In the $\mathrm{SH}$ there is a major storm track which begins in the eastern South Atlantic and generally extends towards the seas south of Australia, although its eastward extent is rather variable. In the observational analyses (Fig. 10a) the strongest section 


\section{(a) CONTROL}

Summer (DJF)

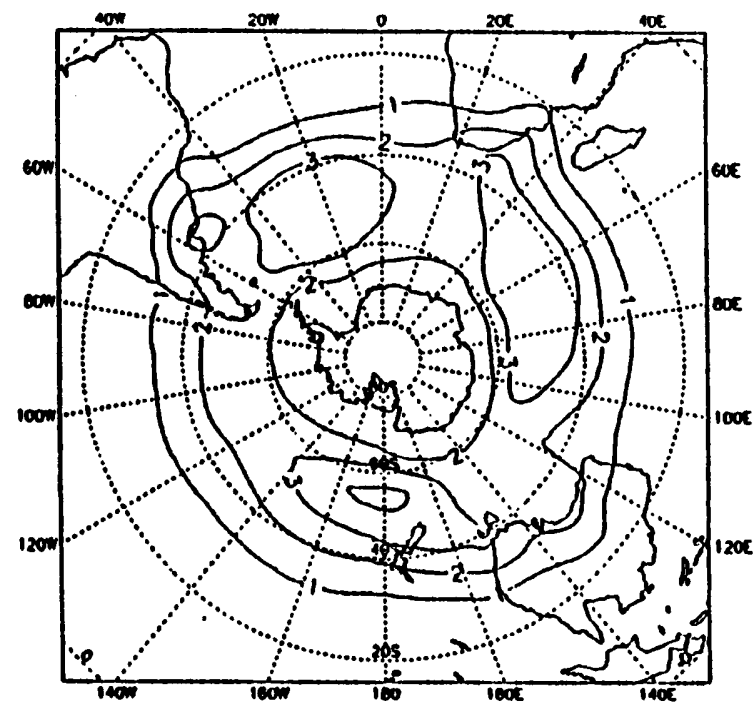

winter (JJA)

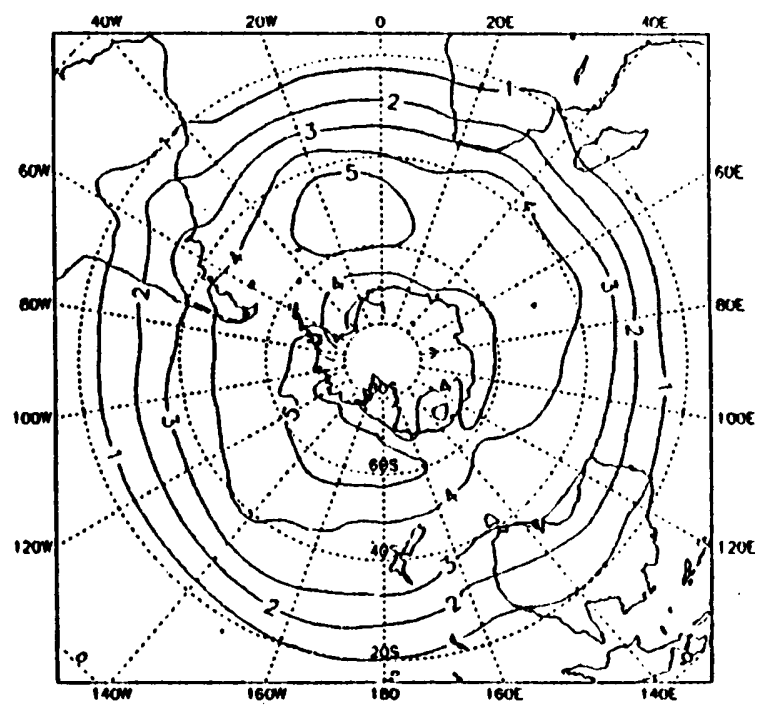

\section{Summer (DJF)}

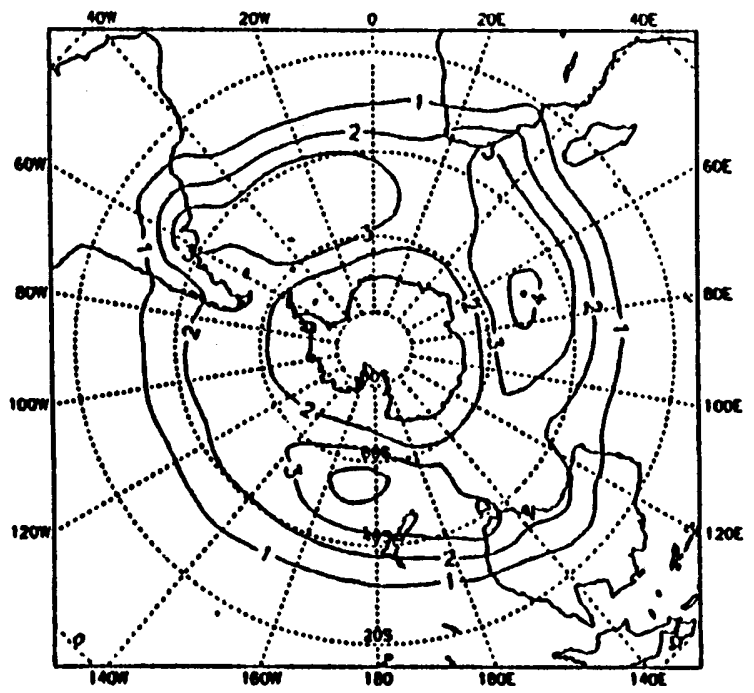

(b) NOICE

\section{winter (JJA)}

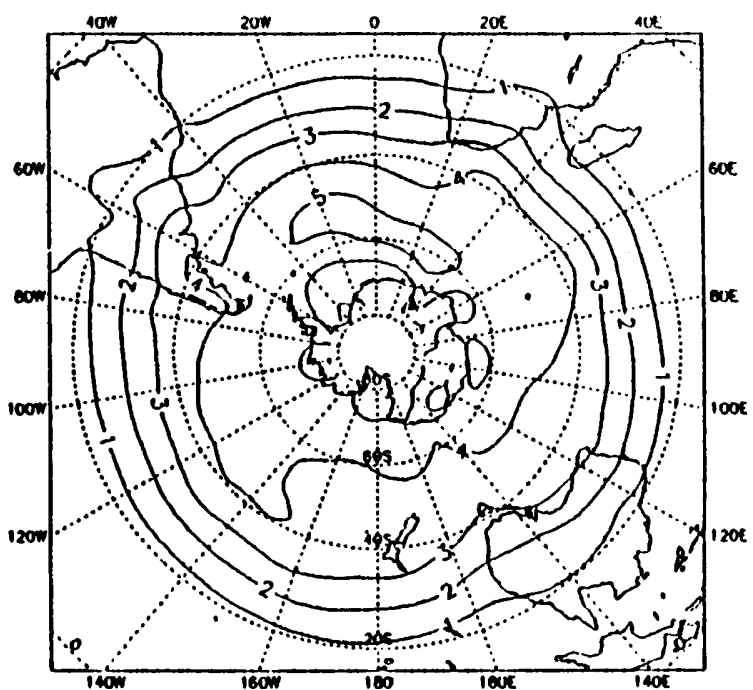

Fig. 8a, b. Filtered standard deviation 3-9 days of mean sea level pressure for summer and winter: a control and b NOICE. The contour interval is $1 \mathrm{hPa}$

of the storm track is located in the southern Indian Ocean, between $40^{\circ} \mathrm{E}$ and $90^{\circ} \mathrm{E}$. The maximum intensity is similar in both seasons, but in summer the storm track is more zonally elongated and in winter the activity extend over broader latitudes. In order to determine the role of sea-ice on the storm track, Fig. 10 shows also the 3-9 days bandpass filtered standard deviations of $300 \mathrm{hPa}$ geopotential height for the control (Fig. 10b) and NOICE (Fig. 10c) simulations and the anomalies NOICE minus control (Fig. 10d). The observed geographical distribution in winter of the high-frequency variability seems to be reasonably reproduced in the model, but the standard deviation is underestimated. In the NOICE case the maximum intensity in the Indian Ocean is similar to the control, although the main storm track shifts slightly poleward and is less elongated eastward when sea-ice is eliminated. In general over the Indian Ocean the NOICE simulation exhibits less variability equatorward of about $50^{\circ} \mathrm{S}$ and increased variability to the south (see Fig. 8d). Over the southern Atlantic and Pacific Oceans the anomalies are predominantly negatives (i.e. the variability is diminished in 


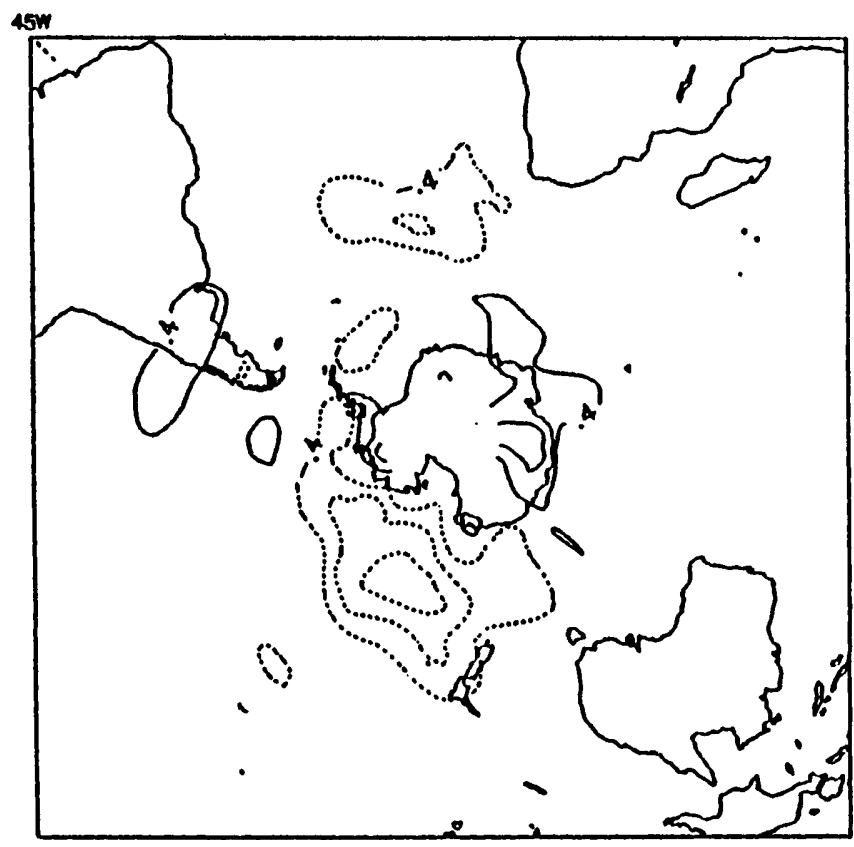

Fig. 9. Changes (NOICE minus control) in the 3-9 days filtered standard deviation of mean sea level pressure for winter. Contours every $0.4 \mathrm{hPa}$; negative contours are dashed. The zero contours are omitted

NOICE), especially near $50^{\circ} \mathrm{W}$ and $170^{\circ} \mathrm{W}$. In summer (not shown), the changes in the storm track are rather difficult to see. It is worth noting that the structure of the changes in variance at the surface and $300 \mathrm{hPa}$ are very similar. A similar "barotropic" response was found by Menéndez (1994) in a sensitivity study, performed with a regional model, of the synoptic evolution of subAntarctic storms to different sea-ice conditions.

\subsection{Energy cycle}

The atmospheric circulation is maintained against the dissipative effects of friction by converting potential energy into kinetic energy of atmospheric motion through baroclinic instability. In the midlatitudes, the baroclinic instability is manifested through the generation of active cyclones and anticyclones. These eddies carry heat poleward and upward, with the main centres of heat fluxes concentrated into the storm track. According to SW93 and our results, sea-ice may affect the cyclone behaviour in the Antarctic periphery. The collective effect of individual cyclones in the circumpolar trough can be linked to circulation changes over extensive areas of the SH (Meehl, 1991).

We now examine some aspects of the simulated energy cycle and its changes from the NOICE to the control case. Figure 11 shows the zonal averages of the zonal and eddy potential and kinetic energies for winter, for both the control and NOICE simulations. The mean zonal available potential energy (Fig. 11a) depends on the north-south variance of the temperature at each level, and is smaller in the NOICE case, south of about $60^{\circ} \mathrm{S}$. The eddy available potential energy (Fig. 11b) is proportional to the east-west variance of temperature, and it is also weaker in NOICE. The main differences from the control to the NOICE case are observed between $50^{\circ} \mathrm{S}$ and $70^{\circ} \mathrm{S}$. Some of the eddy available potential energy is transformed into kinetic energy of the perturbations (Fig. 11c), through baroclinic instability. The effect of removing sea-ice is to diminish the kinetic energy of the growing disturbances, mainly poleward of about $50^{\circ} \mathrm{S}$ and also in the region of the subtropical jet (near $30^{\circ} \mathrm{S}$ ). The zonal mean kinetic energy (Fig. 11d) exhibits a rise in the zone of the subtropical branch of the westerlies and a decrease poleward of $30^{\circ} \mathrm{S}$, especially evident in the latitudes of the polar jet and the storm track.

Figure 12 shows the annual march of the average between $50^{\circ} \mathrm{S}$ and $65^{\circ} \mathrm{S}$ of the rate of conversion from eddy potential energy to eddy kinetic energy. This conversion is associated with the sinking of colder air and rising of warmer air at different longitudes, and can be considered as a measure of the mean intensity of baroclinic processes between the region of the storm track and the subpolar trough. The control curve has two maxima in April-May and October, as a manifestation of the SAO in the model. In the NOICE simulation, the rate of the baroclinic energy conversions is weaker from March to October and tends to be stronger in summer. These variations are consistent with the SW93 and MSLT99 results concerning the intensity of the perturbations. They found that cyclones become weaker in winter when the sea-ice concentration is reduced. We recognize that the limited length of the simulations may also affect these results, but their physical consistency has to be noted and tends to balance this statistical weakness.

\section{Summary and conclusions}

The high latitudes of the $\mathrm{SH}$ are a sensitive region of the globe where perturbation experiments to large-scale modifications of the climatic boundary conditions show a major response. Sea-ice is often thought to play a dominant role in this high-latitude response. The role of sea-ice is primarily thermodynamical, through a modification of the surface energy balance, but the associated changes in the atmospheric dynamics may also be important. This importance of the sea-ice on the atmospheric dynamics was studied here, using a version of the LMD GCM, through a sensitivity experiment in which all Antarctic sea-ice was replaced by open ocean. The use of this rather artificial and large surface anomaly has the advantage of reducing the noise level of the results and thus increases their reliability and significance. However, it must be emphasized that in order to make a realistic simulation of the climate conditions over an ice-free Southern Ocean it will be necessary to couple the atmospheric model with oceanic models, including sea-ice.

The potential for sea-ice to modify the transient circulation is a question worthy of consideration. It is 


\section{a) ECMWF}

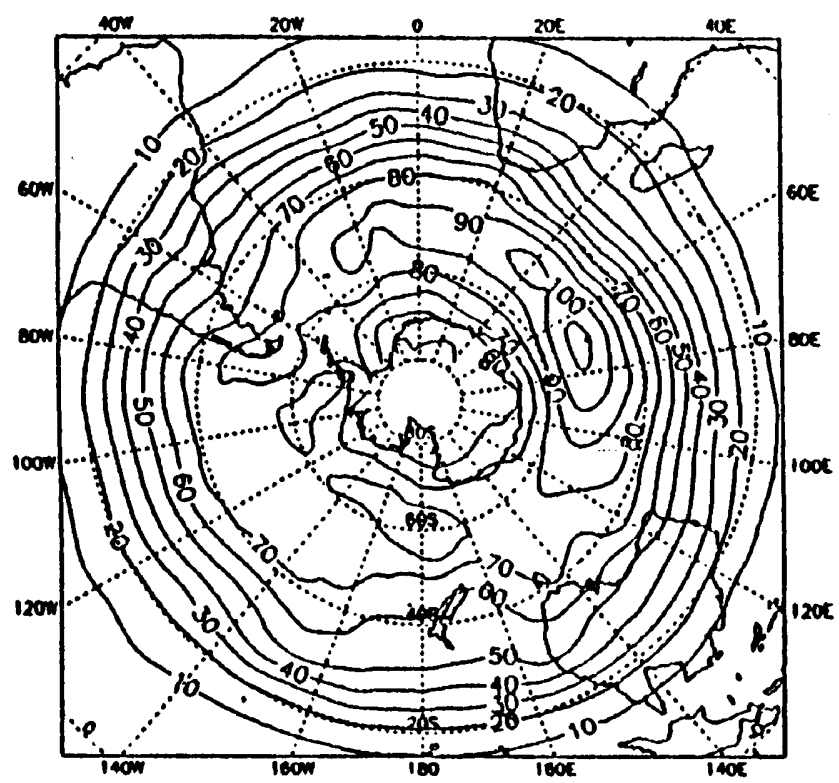

\section{c) NOICE}

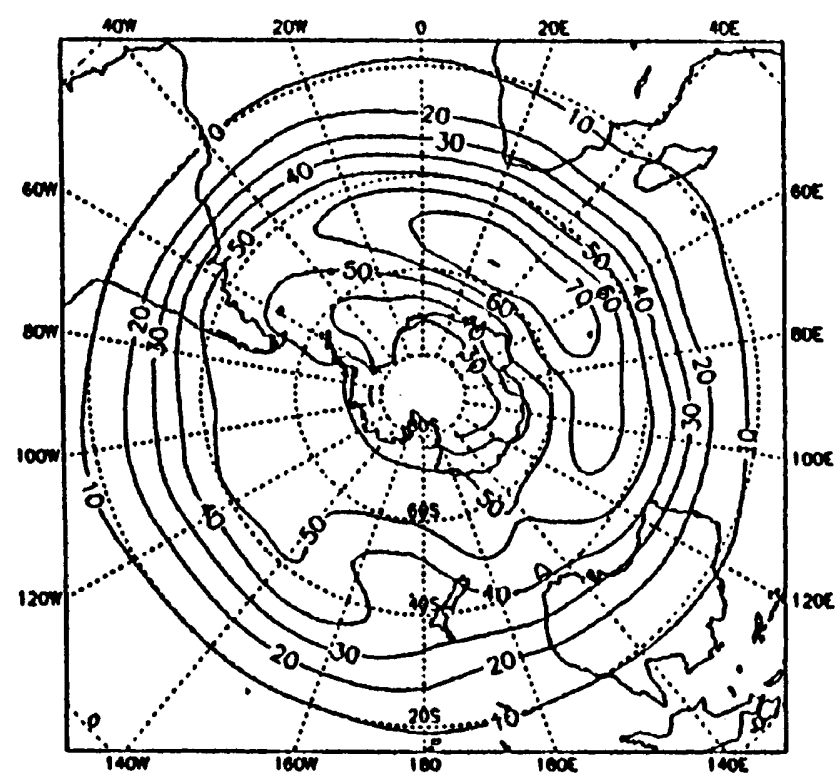

b) CONTROL

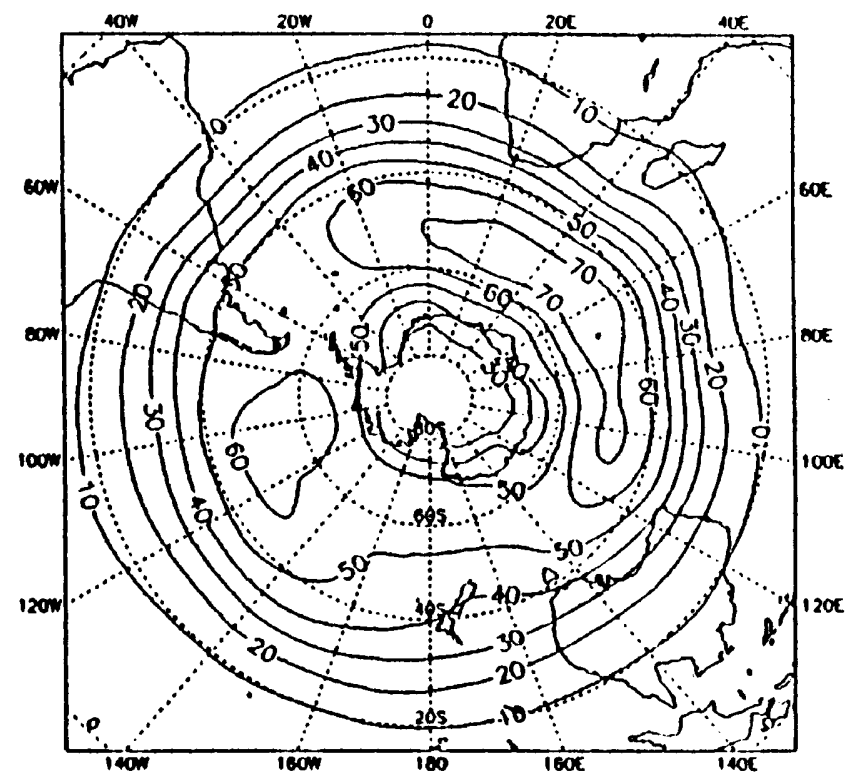

d) NOICE - CONTROL

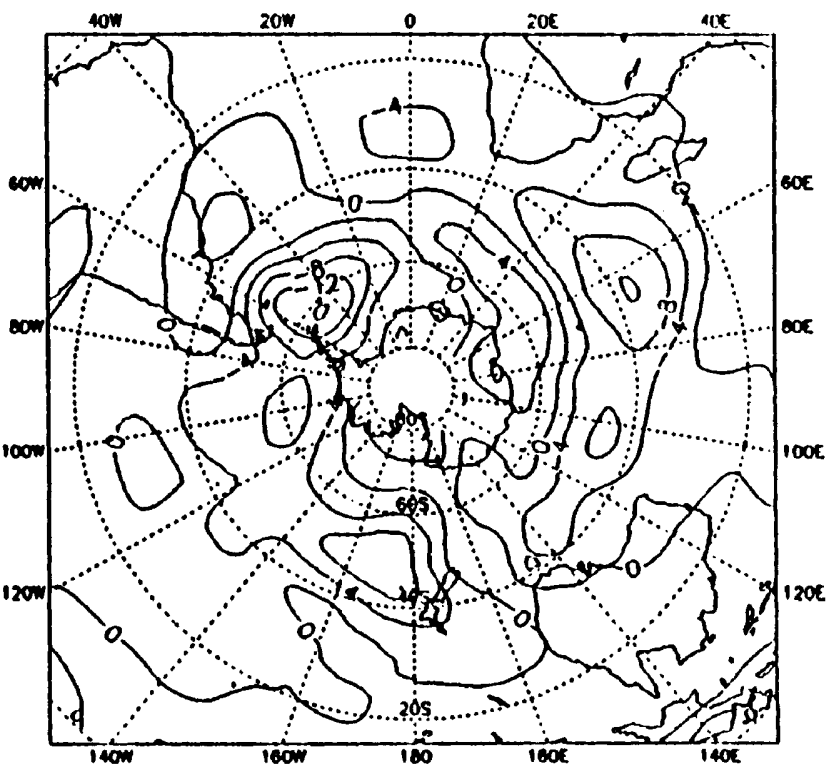

Fig. 10a-d. Filtered standard deviation (3-9 days) of $300 \mathrm{hPa}$ geopotential height for winter: a ECMWF analysis, b control simulation, c NOICE simulation and $\mathbf{d}$ anomaly. The contour interval is $10 \mathrm{~m}$ in $\mathbf{a}, \mathbf{b}$ and $\mathbf{c}$ and $4 \mathrm{~m}$ in $\mathbf{d}$

now well established that the sea-ice characteristics utilized in climate models has considerable impact upon the simulated climate (e.g. Mitchell and Senior, 1989; Simmonds and Budd, 1991) as well as the climatology of the model's cyclonic systems (SW93). Apart from a modulating effect on latent and sensible heat fluxes, anomalous sea-ice distribution can also alter the position and strength of baroclinic zones in the high southern latitudes (Simmonds and Budd, 1991). Seaice also acts as a mechanical forcing. The replacement of sea-ice by open ocean is accompanied also by a substantial reduction in surface roughness. Mitchell and Senior (1989) found that the changes in surface drag contribute substantially to the response to reduced seaice extent. Any of these factors have the potential to alter cyclone characteristics. Alteration of extratropical transient behaviour may well have broader effects, given the primary role of the synoptic systems in the poleward heat and momentum transport in the SH (MSLT99).

The simulation of the atmospheric dynamics and thermodynamics may be sensitive to resolution. According to previous studies, even the coarse-resolution 

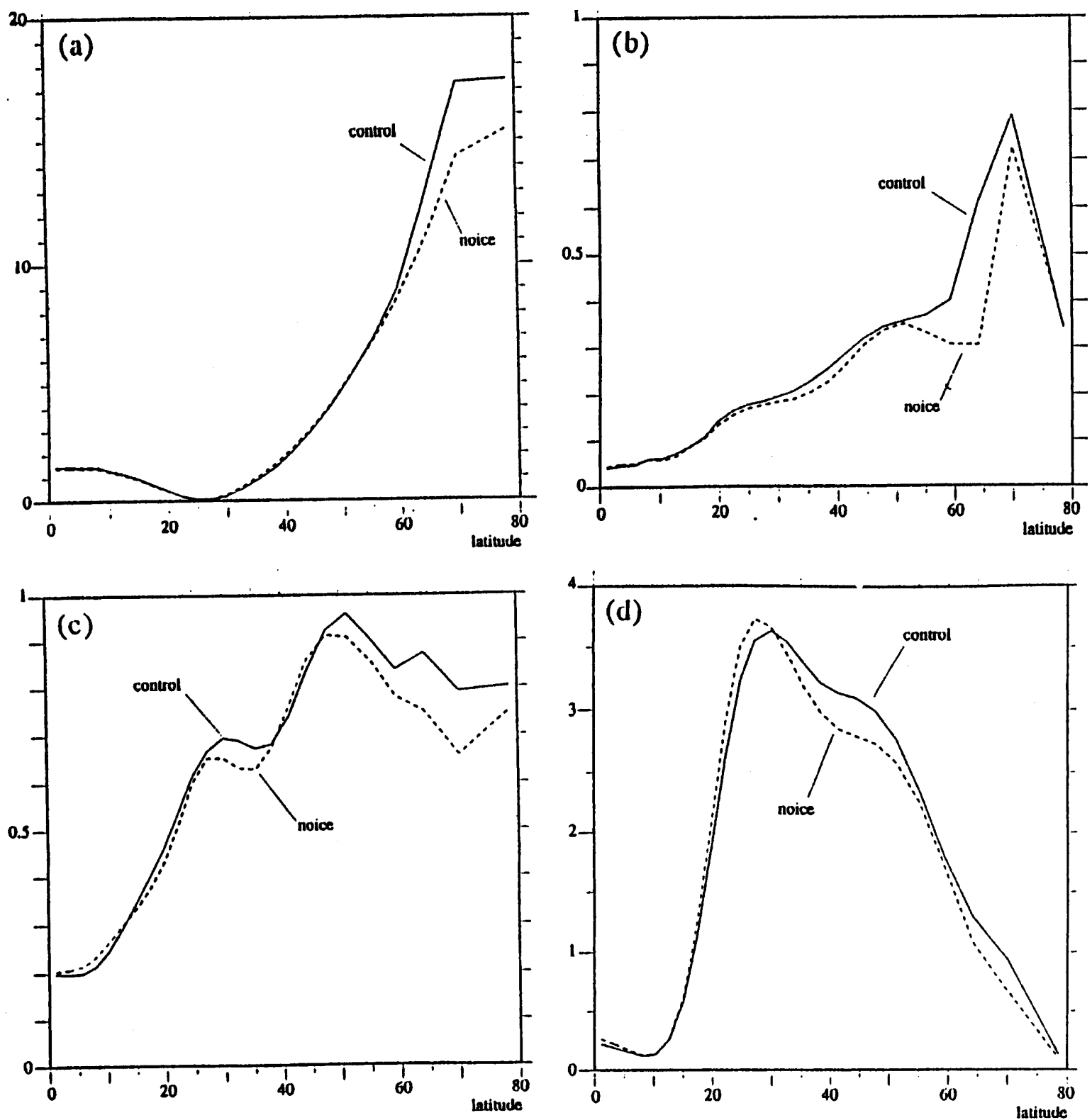

Fig. 11a-d. Zonally and vertically integrated basic forms of energy for winter, in $10^{6} \mathrm{Jm}^{-2}$, for the control (solid line) and the NOICE (dashed line) simulations: a available potential energy of the mean

zonal flow, $\mathbf{b}$ available potential energy of the perturbations, $\mathbf{c}$ kinetic energy of the perturbations, and $\mathbf{d}$ kinetic energy of the mean zonal flow

global models can represent many aspects of synoptic weather systems with useful accuracy. For example, Tzeng et al. (1993) found that a low-resolution GCM (in their case the CCM1 with R15 resolution, equivalent to a grid mesh of $4.5^{\circ}$ latitude by $7.5^{\circ}$ longitude) can well simulate, to some extent, the dynamics of Antarctic climate not only for the synoptic scale, but also for some mesoscale features (mesoscale cyclogenesis). Obviously increased resolution would improved the simulation of the transient high-frequency eddies, but the suggestion is that low-resolution GCMs are capable of providing guidance in the study of the synoptic circulation in the southern extratropics. Moreover, according to SW93 the use of low-resolution models in sensitivity experiments such as this (rather than a more demanding forecasting) is not a serious handicap to the interpretation of the results. The baroclinicity is tied up with cyclogenesis, and cyclones in turn with energy and momentum transports. Given that these transports are higher order moments, their simulation would be expected to be rather sensitive to resolution. However, the high-resolution sensitivity experiment described in MSLT99 exhibits changes in eddy activity qualitatively consistent with our results. As a consequence, the results of this study are unlikely to be an artefact of an inadequate model resolution.

The sea-ice has a strong effect on temperatures along the Antarctic coasts because the layer of ice insulates the surface of the ocean. The differences between the control and perturbed simulations display some longitudinal 


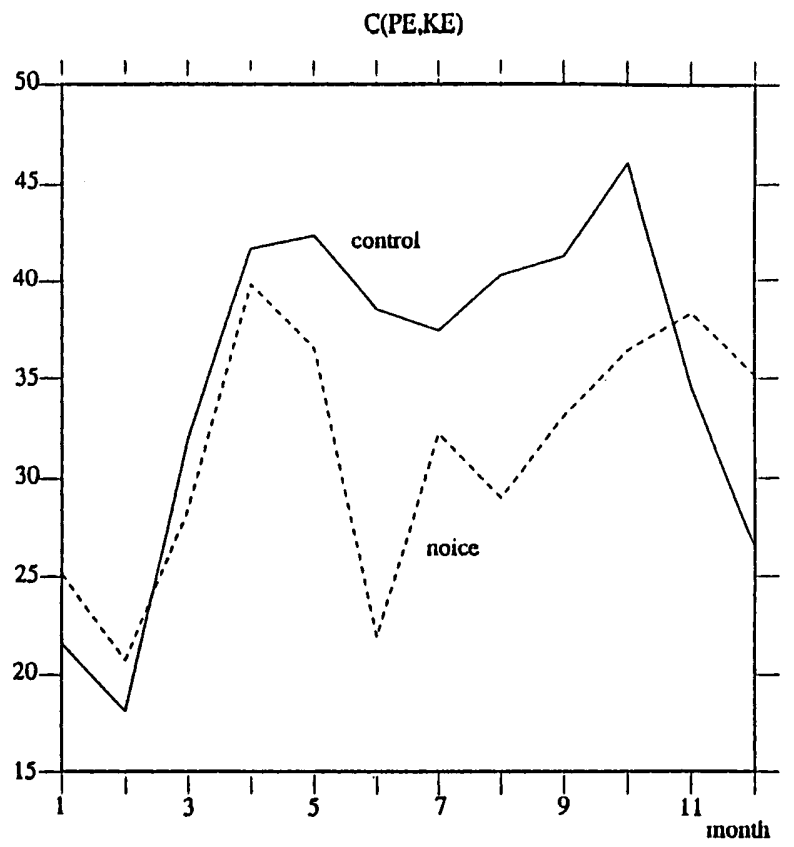

Fig. 12. Seasonal variation of the rate of conversion between eddy potential energy and eddy kinetic energy, averaged between $50^{\circ} \mathrm{S}$ and $65^{\circ} \mathrm{S}$, in $0.1 \mathrm{Wm}^{-2}$

asymmetry, partly due to the geography of Antarctica and to the sea-ice distribution around the continent. In the NOICE case, the zones with larger surface heat fluxes displace poleward and the upward fluxes become strong at the coast of Antarctica. As a consequence, there is an atmospheric warming over the ice-free ocean surface, mainly confined to the high latitudes poleward of $60^{\circ} \mathrm{S}$ and to the lower levels of the troposphere. While sea level pressure shows a large decrease in some sectors, other neighbouring areas experience compensating increases. Thus, the zonal mean in the latitude of the circumpolar trough is similar in both simulations. In general, the surface pressure response agrees with some previous studies (e.g. Simmonds and Dix, 1986, removed all SH sea-ice, finding both rises and falls in surface pressure in the region from which sea-ice was removed).

Many of the anomalies presented here show a considerable contrast in the north-south direction. For example, an opposition in the zonal wind response between mid- and subpolar latitudes in the Pacific sector has been found in winter. In the NOICE simulation the polar jet is weaker and the subtropical jet is stronger. Not surprisingly, the changes are much weaker in summer. This might suggest that the changes in temperature taking place along the Antarctic coast in winter do not just affect the high-latitude processes, but also the circulation in the mid-latitudes areas of the SH. It is worth noting that recent observational research suggests that anomalies in sea-ice could be associated with largescale adjustments in the SH circulation. For example, Turner et al. (1997) found a significant correlation between observed temperature anomalies on the Antarctic Peninsula and $500 \mathrm{hPa}$ height anomalies across the South Pacific between $30^{\circ}-50^{\circ} \mathrm{S}$ during winter.
According to our results, it seems likely that anomalous conditions in the cyclonic activity are related to changes in the sea-ice extent. Extratropical storms are observed to evolve in the Antarctic periphery within the circumpolar trough (e.g. Jones and Simmonds, 1993). This zone is characterized by a strong meridional thermal contrast linked with the large heat fluxes from the ocean. When sea-ice is eliminated, the wintertime short scale perturbations exhibit less surface pressure variability near and to the north of the control ice edge. The most affected areas are found in the western sector of the circumpolar trough, over the Bellingshausen/ Amundsen and Weddell seas. Over the Antarctic coasts the changes are lesser. However, a longitudinal sector over eastern Antarctica shows up as a region of increased variability. Another region with enhanced variability appears over South America at about $40^{\circ} \mathrm{S}$. In winter the main storm track over the Indian Ocean shifts poleward and is less elongated eastward and the Pacific and Atlantic Oceans exhibit less synoptic variability in the NOICE simulation. The anomalies in summer are much weaker.

The simulated energy cycle was evaluated. In general the effect of removing sea-ice is to diminish the zonal and eddy potential and kinetic energies, in the middle to high latitudes. The zonal mean of all the potential energy of the mean zonal flow, the available potential energy of the perturbations, the kinetic energy of the perturbations and the kinetic energy of the mean zonal flow tend to be weaker in NOICE. The zonal mean patterns of the simulated energy cycle reveal also that the baroclinic processes in the NOICE simulation are in general weaker between the latitudes of the storm track and the circumpolar trough. The weaker eddy activity in NOICE is also manifested through a weakness of the half-yearly cycle of the circumpolar trough and of the baroclinic processes.

In general, the changes in zonal wind, eddy activity and energy cycle are consistent with the study of MSLT99 who used a higher resolution version of this model in a 10-y experiment with full seasonal cycle. We could infer that our findings would not be associated neither with deficiencies in the resolution nor with the inherent variability of the simulated climate in high latitudes. The results also confirm some features obtained previously by SW93. These authors have shown that, over most of the sea-ice area, the cyclonic systems became weaker as the sea-ice concentration was reduced. They also found a tendency for more cyclones over the Antarctic coastal zone and fewer cyclones to the north. Simulations of subAntarctic storms with regional models can be useful to indicate what kind of systems should be expected over an ice-free ocean. Menéndez (1994) reported on a simulation of two late winter storms with a high-resolution regional model (the CIMA version of the LAHM/GFDL model). The role of sea-ice was evaluated by performing a series of sensitivity tests in which surface heat and momentum fluxes were affected. The regional model also produced weaker storms with a kinetic energy reduction throughout the troposphere when conditions were set to that 
appropriate to the open ocean, supporting the conclusion of SW93 and our results.

We emphasize here that the role of the atmospheric circulation needs to be considered when studying climate sensitivity in the SH. Of course, there are nonlinear interactions within the climate system, and thus there is a limit to the extent to which high-latitude atmospheric anomalies can be explained wholly in terms of the sea-ice conditions. The divergence of the various models in response to climate perturbation is often attributed to thermodynamic feedbacks (i.e. surface albedo, clouds) or to the role of the ocean. However, atmospheric dynamics can affect and be affected by the sea-ice distribution and concentration, and may be responsible of other important feedback effects. For example, Turner et al. (1997) propose a possible positive feedback on the western side of the Antarctic Peninsula. This feedback relates periods of northerly (southerly) flow with negative (positive) sea-ice anomalies. A relationship between winter season ice extent anomalies and the meridional component of the geostrophic flow seems evident (Harangozo, 1994). MSLT99 proposed other feedback mechanisms regarding the meridional transport of heat and other properties by the atmosphere. Further investigation of these processes using different climate models is clearly needed.

Acknowledgements. The authors would like to thank Dr. Ian Simmonds and an anonymous reviewer for their helpful comments. The research for this paper was supported by the European Commission under contract CT94-0111 and the ANPCyT, Argentina (BID 802/OC-AR-PICT 583).

Topical Editor D. Webb thanks I. Simmonds and P. Valdes for their help in evaluating this paper.

\section{References}

Berbery, E. H., and C. S. Vera, Characteristics of the Southern Hemisphere winter storm track with filtered and unfiltered data, J. Atmos. Sci., 53, 468-481, 1996.

Boville, B. A., Sensitivity of simulated climate to model resolution, J. Clim., 4, 469-485, 1991.

Bromwich, D. H., Mesoscale cyclogenesis over the southwestern Ross Sea linked to strong katabatic winds, Mon. Weather Rev., 119, 1736-1752, 1991.

Carleton, A. M., Antarctic sea-ice relationships with indices of the atmospheric circulation of the Southern Hemisphere, Clim. Dyn., 3, 207-220, 1989.

Carleton, A. M., Synoptic interactions between Antarctica and lower latitudes, Aust. Meteorol. Mag., 40, 129-147, 1992.

Carril, A. F., C. G. Menéndez, and M. N. Nuñez, Climate change scenarios over the South American region: an intercomparison of coupled general atmosphere-ocean circulation models, Int. J. Climatol., 17, 1613-1633, 1997.

Chalita, S., and H. Le Treut, The albedo of temperature and boreal forest and the Northern Hemisphere climate: a sensitivity experiment using the LMD GCM, Clim. Dyn., 10, 231-240, 1994.

Fouquart, Y., and B. Bonnel, Computations of solar heating of the Earth's atmosphere: a new parametrization, Beitr. Phys. Atmos., 53, 35-62, 1980.

Godfred-Spenning, C. R., and I. Simmonds, An analysis of Antarctic sea-ice and extratropical cyclone associations, Int. J. Climat., 16, 1315-1332, 1996.
Harangozo, S. A., Interannual atmospheric circulation-sea-ice extent relationships in the Southern Ocean: an analysis for the west Antarctic Peninsula region, Sixth Conf. on Climate Variations, A. M. S., January 23-28, Nashville, Tennessee, 364-367, 1994.

Harangozo, S. A., S. R. Colwell, and J. C. King, Interannual and long-term air temperature variability in the southern Antarctic Peninsula from a reconstructed record for eastern Alexander Island, Sixth Conf. on Climate Variations, A. M. S., January 2328, Nashville, Tennessee, 250-251, 1994.

Harzallah, A., and R. Sadourny, Internal versus SST-forced atmospheric variability as simulated by an atmospheric general circulation model, J. Clim., 8, 474-495, 1995.

Hoskins, B. J., I. N. James, and G. H. White, The shape, propagation, and mean-flow interaction of large-scale weather systems, J. Atmos. Sci., 40, 977-988, 1983.

James I., and L. Gray, Concerning on the effect of surface drag on the circulation of baroclinic planetary atmosphere, Qt. J.R. Meteorol. Soc., 112, 1231-1250, 1986.

Jones, D. A., and I. Simmonds, A climatology of Southern Hemisphere extratropical cyclones, Clim. Dyn., 9, 131-145, 1993.

Katzfey, J. J., and K. L. McInnes, GCM simulations of eastern australian cutoff lows, J. Clim., 9, 2337-2355, 1996.

Kuo, H. L., On formation and intensification of tropical cyclones through latent heat release by cumulus convection, J. Atmos. Sci., 22, 40-63, 1965.

Le Treut, H., and E. Kalnay, Comparison of observed and simulated cyclone frequency distribution as determined by an objective method, Atmósfera, 3, 57-71, 1990.

Le Treut, H., Z. X. Li, O. Boucher, G. Seze, and M. Doutriaux, Some aspects of the LMD GCM verification and development: clouds and radiative budget, Abstr. First International AMIP Scientific Conf., Monterey, California, 1995.

Li, Z. X., and H. Le Treut, Cloud-radiation feedbacks in a general circulation model and their dependence on cloud modelling assumptions, Clim. Dyn., 7, 133-138, 1992.

Meehl, G. A., A reexamination of the mechanism of the semiannual oscillation in the Southern Hemisphere, J. Clim., 4, 911-926, 1991.

Menéndez, C. G., Impacto del hielo marino sobre dos ciclones subantarticos, Meteorologica, 19, 43-51, 1994.

Menéndez, C. G., V. Serafini, and H. Le Treut, The effect of sea ice on the transient atmospheric eddies of the Southern Hemisphere, Clim. Dyn., in press, 1999.

Mitchell, J. F. B., and T. S. Hills, Sea-ice and the antarctic winter circulation, a numerical experiment, Qt. J. R. Meteorol. Soc., 112, 953-969, 1986.

Mitchell, J. F. B., and C. A. Senior, The antarctic winter; simulations with climatological and reduced sea-ice extents, Qt. J. R. Meteorol. Soc., 115, 225-246, 1989.

Morcrette, J. J., Radiation and cloud radiative properties in the ECMWF operational weather forecast model, J. Geophys. Res., 96, 9121-9132, 1990.

Murakami, M., Large-scale aspects of deep convective activity over the GATE area. Mon. Weather Rev., 107, 994-1013, 1979.

Royer, J. F., S. Planton, and M. Déqué, A sensitivity experiment for the removal of Arctic sea ice with the French spectral general circulation model, Clim. Dyn., 5, 1-17, 1990.

Sadourny, R., and K. Laval, January and July performance of the LMD general circulation model, in, New perspectives in climate modelling, Ed. A. Berger and C. Nicolis, Elsevier, Amsterdam, 1984.

Schwerdtfeger, W., The seasonal variation of the strength of the southern circumpolar vortex, Mon. Weather Rev., 88, 203-208, 1960.

Schwerdtfeger, W., and F. Prohaska, The semiannual pressure oscillation, its cause and effects. J. Meteorol., 13, 217-218, 1956.

Simmonds, I., The effect of sea-ice on a general circulation model of the southern hemisphere, in, Sea level, ice, and climate change. 
Proc. IUGG Canberra Symp., December 1979. IAHS Publ. 131, 193-206, 1981.

Simmonds, I., and W. F. Budd, Sensitivity of the Southern Hemisphere circulation to leads in the Antarctic pack ice, $Q t$. J. R. Meteorol Soc., 117, 1003-1024, 1991.

Simmonds, I., and M. Dix, The circulation changes induced by the removal of antarctic sea-ice in a July general circulation model, Proc. Second International Conference on Southern Hemisphere Meteorology, Wellington, New Zealand, December 1986. American Meteorological Society, pp 107-110, 1986.

Simmonds, I., and D. A. Jones, The mean structure and temporal variability of the semiannual oscillation in the southern extratropics, Int. J. Climatol., 18, 473-504, 1998.

Simmonds, I., and $\mathrm{X}$. Wu, Cyclone behaviour response to changes in winter southern hemisphere sea-ice concentration, $Q t . J . R$. Meteorol. Soc., 119, 1121-1148, 1993.

Simmons, A. J., and B. J. Hoskins, The life cycles of some nonlinear baroclinic waves, J. Atmos. Sci., 36, 414-432, 1978.

Streten, N. A., and D. J. Pike, Characteristics of the broad scale Antarctic sea-ice extent and the associated atmospheric circu- lation, 1972-1977, Arch. Meteorol. Geophys. Biokl., 29, 279299, 1980

Trenberth, K. E., Storm tracks in the Southern Hemisphere, J. Atmos. Sci., 48, 2159-2178, 1991.

Turner, J., J. King, S. Harangozo, W. Connolley, and G. Marshall, Major changes in the climate of the Antarctic Peninsula during the last 50 years, Seventh Conference on Climate Variations, A. M. S., February 2-7, Long Beach, California, J88-J91, 1997.

Tzeng, R. Y., D. H. Bromwich, and T. R. Parish, Present-day Antarctic climatology of the NCAR Community Climate Model Version 1, J. Clim., 6, 205-226, 1993.

Van Loon, H., Meteorology of the Southern Hemisphere, Meteor. Monogr., 35, Ed. C. W. Newton, American Meteorological Society, pp 59-99, 1972.

Van Loon, H., and J. C. Rogers, Interannual variations in the halfyearly cycle of pressure gradients and zonal wind at sea level in the Southern Hemisphere, Tellus, 36A, 76-86, 1984.

Xu, J.-S., H. Von Storch, and H. van Loon, The performance of four spectral GCMs in the Southern Hemisphere: the January and July climatology and the semiannual waves, J. Clim., 3, 53-70, 1990. 